\title{
The Effect of Indicators of Systemic Inflammatory Response on Survival in Glioblastoma Multiforme
}

\author{
Ozlem MERMUT, Berrin INANC \\ University of Health Sciences, Istanbul Training and Research Hospital, Clinic of Radiation Oncology, Istanbul, Turkey
}

Corresponding author: Ozlem MERMUT mermutozlem@gmail.com

\section{ABSTRACT}

AIM: To evaluate the prognostic value of preoperative neutrophil-to-lymphocyte ratio and platelet-lymphocyte ratio in glioblastoma multiforme patients.

MATERIAL and METHODS: A total of 75 patients retrospectively analysed. The complete blood count of the patients was analysed before surgery. In our study, cut-off values for PLR 150 (platelet-lymphocyte ratio) and NLR 4 (neutrophil-to-lymphocyte ratio) were found to be significant by creating the ROC curve. Overall survival (OS) was calculated from surgery to death or the last contact. Progression-free survival (PFS) was calculated from surgery to progression. The last follow-up was November 2018.

RESULTS: The median OS was significantly shorter in PLR>150 patients ( $p=0.005 ; 10$ vs 17 months). And the median OS was significantly shorter in NLR $>4$ patients too ( $p=0.010 ; 11$ vs 17 months). In multivariate analysis, Karnofsky performance score $<70$ (HR:2.96, 95\% Cl:1.68-5.21; $\mathrm{p}<0.001)$, type of surgical resection (HR:2.32, 95\% Cl:1.35-3.98; $\mathrm{p}=0.002)$ were statistically significant for PFS. In multivariate analysis, KPS $<70$ (HR:2.72, 95\% Cl:1.30-5.67; $\mathrm{p}<0.007)$, type of surgical resection (HR:2.09, 95\% Cl:1.103.95; $p=0.023), N L R>4$ (HR:2.14, 95\% Cl:1.11-4.14; $p=0.023)$ were statistically significant for OS were found to be independent prognostic factor.

CONCLUSION: The presence of $70<$ KPS and type of surgical resection in patients with GBM had a negative effect on PFS. NLR $>4$, $70<\mathrm{KPS}$, type of surgical resection were independent prognostic factors that negatively affect for the OS.

KEYWORDS: Glioblastoma multiforme, Pretreatment neutrophil-to-lymphocyte ratio, platelet-to-lymphocyte ratio, Survival

\section{口 INTRODUCTION}

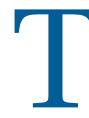
The World Health Organization describes glioblastoma as a malignant, class IV tumour with a high degree of mitosis and necrosis (10). The most common malignant primary brain tumour in adults is glioblastoma (10). Glioblastoma multiforme (GBM), all cancer related deaths 3-4\% of that causes the most malignant form (10). The median survival after diagnosis is 12 months just radiotherapy and 14,5 months with radiochemotherapy in GBM patients (15). The standard therapy for GBM is maximum total resection followed by radiation therapy concurrent with temozolomide (TMZ) and subsequent adjuvant TMZ chemotherapy (Stupp protocol) (15). Recently, evidence has shown that preoperative haematological markers related to nutrition, clotting and inflammation are predictive and prognostic factors of cancers $(7,13)$. Neutrophil-to-lymphocyte ratio (NLR), platelet-to-lymphocyte ratio (PLR), haematological indicator of systemic inflammation. Studies in many various cancers have demonstreated the relationship between high NLR and PLR and poor prognosis. A high NLR and PLR gastrointestinal tumours, such as prostate cancer and lung cancer is closely related to a poor prognosis in solid malignancies $(3-5,16-18,20,22)$. PLR and NLR as prognostic marker in glioblastomas in recent years has been described. NLR and PLR are the determinants of host inflammation $(1,9,14)$.

\section{MATERIAL and METHODS}

In this study, 122 GBM patients were admitted to our institution 
between the years 2011-2018 for postoperative radiotherapy purposes. 75 of them had the conditions to be analysed. We took medical records indicating the patient's age, gender, histopathology, magnetic resonance imaging (MRI) and computed tomography (CT) scans and follow-up data in our clinical files. Patients with complete blood count results prior receiving corticosteroid therapy and surgery were incorporated in the study. The exclusion criteria were: 1)-hematological diseases, 2)-autoimmune diseases, 3)-metabolic diseases, 4)-existing infections, 5)-patients treated with glucocorticoid or anti-inflammatory drugs.

Overall survival was defined from surgery to death or the last contact, and was determined as the last follow-up of November 2018. Progression-free survival (PFS) was calculated from surgery to progression. Tumor diameter was measured based on preoperative MRI scans. Newly improving or worsening neurological symptoms, tumour growth of $25 \%$ in the MRI were assumed as progression.

Complete blood count and biochemical tests, was performed with XN-900 Haematology analyser (Symex,Japan). The normal reference range for neutrophils 1,56-6,13 $\times 10^{9} / \mathrm{L}$, for lymphocytes to $1.18-3,57 \times 10^{9} / \mathrm{L}$ and platelets for $142-424$ $\times 10^{9} / \mathrm{L}$. NLR was calculated by dividing the neutrophil count by the lymphocyte count, and the PLR was defined as the absolute platelet count divided by the absolute lymphocyte count.

This study was approved by the local Ethics Committee (2018 /1598).

\section{Statistical Method}

The descriptive statistics were performed using of the data mean, standard deviation, median-minimum-high frequency and ratio values. The distribution of the variables was measured using Kolmogorov Smirnov test. Independent quantitative data analysis Mann-Whitney $U$ test was used. Independent qualitative data analysis chi-square test, chisquare test conditions are not provided, were compared using Fischer's test. The domain level and the cut off value by ROC curve were investigated. Kaplan Meier survival analysis (logrank) was used. Univariate and multivariate Cox proportional hazards models were made. Statistical analysis were performed using SPSS software version 22.0 (IBM SPSS, Armonk, NY, USA) and the level of significance was taken as a $p$ value less than 0.05 .

\section{RESULTS}

Among the 75 patients analysed, 28 (\%37) were female and 47 (\%63) were male. Median age of the patients was $58.0 \pm 13.02$ years (range:19-78). The median follow-up was $12.0 \pm 12.95$ (6-84) months. The median tumour diameter was $4.0 \pm 1.49 \mathrm{~cm}$ $(2.5-9 \mathrm{~cm})$. The most common symptom was headache in 25 $(33 \%)$ patients. Lesion lateralisation was the left hemisphere in $35(47 \%)$ patients and the right hemisphere in 40 (53\%). The most common tumour localisation was temporal lobes in $25(33 \%)$ patients. The parietal lobe 17 (23\%), frontal lobe 14 (19\%) and others 19 (25\%), respectively. The most common symptom was headache 25 (33\%), then power loss 12 (16\%), speech disorder 10 (13\%), balance problems 9 (12\%), vision problems $8(11 \%)$, nausea and vomiting $6(8 \%)$, amnesia 3 (4\%), seizure $2(3 \%)$ respectively. Comorbid diseases were observed in $17(23 \%)$ patients. Essential hypertension $(n=9)$ were the most common comorbid disease. 3 patients had chronic obstructive lung disease, 2 patients cardiac diseases and 3 patients mixed diseases.

Gross total resection was performed in 31 (41\%) patients, subtotal resection was performed 44 (59\%) patients. Postoperatively, all patients received chemoradiotherapy and $69(92 \%)$ patients received adjuvant chemotherapy. Adjuvant temozolomide was given to $69(92 \%)$ patients and median adjuvant treatment cycle was 6 (range: $3-9$ ).

The salvage treatment methods applied to patients after progression were not the same. Chemotherapy, radiotherapy, surgical options one of them applied together or alone. 25 (33\%) patients underwent chemotherapy, 4 (5\%) patients underwent radiosurgery, 8 (11\%) underwent surgery, and 7 (10\%) patients underwent no treatment because of their general condition. No recurrence was observed in 36 (48\%) patients.

In our study, cut-off values for PLR 150 and NLR 4 were found to be significant by creating the ROC curve (Figure 1).

NLR $>4$ values were present in $53(71 \%)$ patients and $N L R<4$ values in $22(29 \%)$ patients. The demographic comparisons of the patients according to NLR ratios are shown in Table I.

Based on PLR>150 values were present in 46 (61\%) patients and PLR<150 in 29 (39\%) patients. The demographic comparisons of the patients according to PLR ratios are shown in Table II.

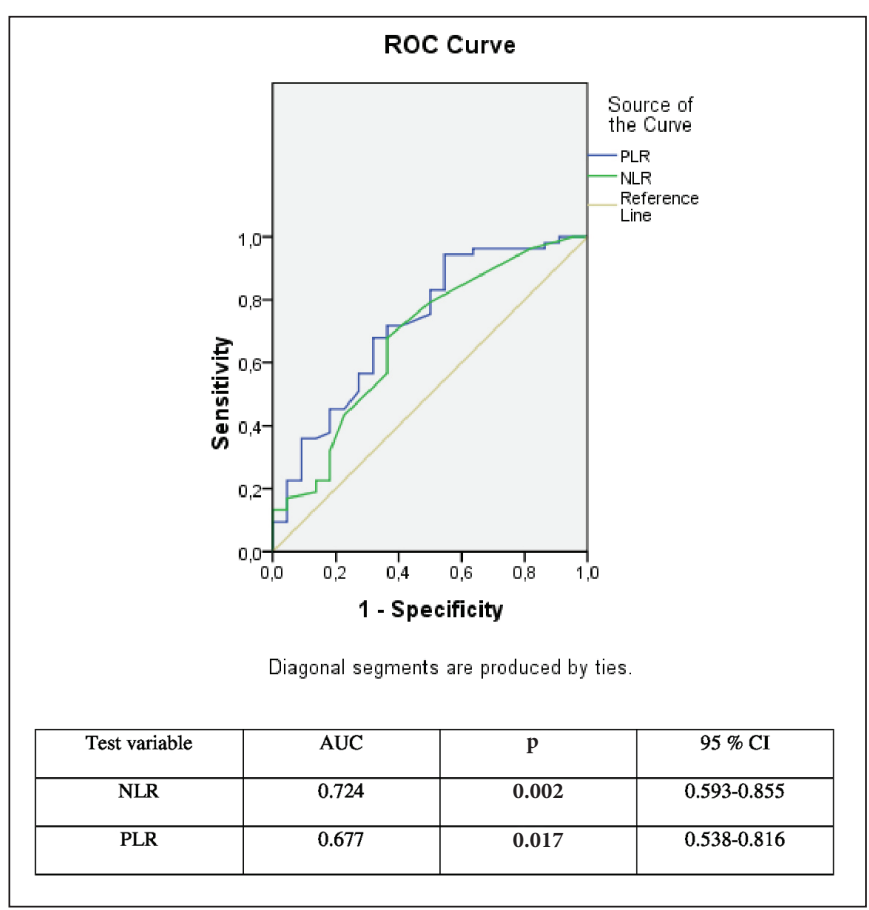

Figure 1: ROC curves for neutrophil-to-lymphocyte ratio (NLR) and platelet-to-lymphocyte ratio (PLR). 
Mermut O. and Inanc B: Survival in Glioblastoma Multiforme

Table I: The Demographic Comparisons of the Patients According to NLR Ratios

\begin{tabular}{|c|c|c|c|c|c|}
\hline & \multicolumn{2}{|c|}{$N L R \leq 4$} & \multicolumn{2}{|c|}{ NLR $>4$} & $\mathbf{p}$ \\
\hline \multicolumn{6}{|l|}{ Age } \\
\hline$\leq 50$ & 9 & 41 & 12 & 23 & 0.109 \\
\hline$>50$ & 13 & 59 & 41 & 77 & \\
\hline Female & 6 & 27 & 22 & 41 & 0.246 \\
\hline Male & 16 & 73 & 31 & 59 & \\
\hline \multicolumn{6}{|l|}{ KPS } \\
\hline$<70$ & 18 & 82 & 28 & 53 & 0.019 \\
\hline Total resection & 9 & 41 & 22 & 41 & 0.962 \\
\hline Subtotal resection & 13 & 59 & 31 & 59 & \\
\hline \multicolumn{6}{|l|}{ Postoperative treatment } \\
\hline Chemoradiotherapy & 21 & 96 & 51 & 96 & 0.877 \\
\hline Only chemotherapy & 1 & 4 & 2 & 4 & \\
\hline \multicolumn{6}{|l|}{ Adjuvan chemotherapy } \\
\hline Present & 21 & 96 & 48 & 91 & 0.477 \\
\hline Absent & 1 & 4 & 5 & 9 & \\
\hline Positive & 11 & 50 & 27 & 51 & \\
\hline Negative & 10 & 46 & 25 & 47 & 0.809 \\
\hline Unknown & 1 & 4 & 1 & 2 & \\
\hline \multicolumn{6}{|l|}{ ATRX } \\
\hline Positive & 11 & 50 & 20 & 38 & \\
\hline Negative & 1 & 4 & 4 & 7 & 0.597 \\
\hline Unknown & 10 & 46 & 29 & 55 & \\
\hline \multicolumn{6}{|l|}{ EGFR } \\
\hline Positive & 10 & 46 & 19 & 36 & \\
\hline Negative & 6 & 27 & 8 & 15 & 0.189 \\
\hline Unknown & 6 & 27 & 26 & 49 & \\
\hline
\end{tabular}

NLR: Neutrophyl to lymphocyte ratio, KPS: Karnofsky performance score, IDH: Isocitrate dehydrogenase, ATRX: $\alpha$ thalassemial mental retardation syndrome $X$-linked, EGFR: Epidermal growth factor. 
Table II: The Demographic Comparisons of the Patients According to PLR Ratios

\begin{tabular}{|c|c|c|c|c|c|}
\hline & \multicolumn{2}{|c|}{ PLR $\leq 150$} & \multicolumn{2}{|c|}{ PLR $>150$} & \multirow{2}{*}{$\mathbf{p}$} \\
\hline & $\mathbf{n}$ & $\%$ & $\mathbf{n}$ & $\%$ & \\
\hline \multicolumn{6}{|l|}{ Age } \\
\hline$\leq 50$ & 14 & 48 & 7 & 15 & 0.002 \\
\hline$>50$ & 15 & 52 & 39 & 85 & \\
\hline \multicolumn{6}{|l|}{ Gender } \\
\hline Female & 10 & 35 & 18 & 39 & 0.685 \\
\hline Male & 19 & 65 & 28 & 61 & \\
\hline \multicolumn{6}{|l|}{ KPS } \\
\hline$<70$ & 26 & 90 & 20 & 44 & $<0.000$ \\
\hline$\geq 70$ & 3 & 10 & 26 & 56 & \\
\hline \multicolumn{6}{|l|}{ Operation type } \\
\hline Total resection & 12 & 41 & 19 & 41 & 0.995 \\
\hline Subtotal resection & 17 & 59 & 27 & 59 & \\
\hline \multicolumn{6}{|l|}{ Postoperative treatment } \\
\hline Chemoradiotherapy & 28 & 97 & 44 & 96 & 0.846 \\
\hline Only chemotherapy & 1 & 3 & 2 & 4 & \\
\hline \multicolumn{6}{|l|}{ Adjuvan chemotherapy } \\
\hline Present & 28 & 97 & 41 & 89 & 0.249 \\
\hline Absent & 1 & 3 & 5 & 11 & \\
\hline \multicolumn{6}{|l|}{ Ki-67 ratio } \\
\hline$\leq 10$ & 8 & 28 & 9 & 20 & 0.419 \\
\hline$>10$ & 21 & 72 & 37 & 80 & \\
\hline \multicolumn{6}{|l|}{ IDH } \\
\hline Positive & 15 & 52 & 23 & 50 & \\
\hline Negative & 13 & 45 & 22 & 48 & 0.926 \\
\hline Unknown & 1 & 3 & 1 & 2 & \\
\hline \multicolumn{6}{|l|}{ ATRX } \\
\hline Positive & 14 & 48 & 17 & 37 & 0.494 \\
\hline Negative & 1 & 3 & 4 & 9 & \\
\hline Unknown & 14 & 48 & 25 & 54 & \\
\hline \multicolumn{6}{|l|}{ EGFR } \\
\hline Positive & 10 & 35 & 19 & 41 & \\
\hline Negative & 7 & 24 & 7 & 15 & 0.609 \\
\hline Unknown & 12 & 41 & 20 & 44 & \\
\hline
\end{tabular}

PLR: Platelet to lymphocyte ratio, KPS: Karnofsky performance score, IDH: Isocitrate dehydrogenase, ATRX: $\alpha$ thalassemial mental retardation syndrome $X$-linked, EGFR: Epidermal growth factor. 
The median PFS for PLR $<150$ was 9 months, NLR $<4$ was 9 months too. These were not statiscically significant. Median PFS was 11 months in patients undergoing total resection and 10 months for Karnofsky performance scare (KPS) $\geq 70$ patients. In univariate analysis KPS $\geq 70 \quad(p=0.002)$, total surgical resection $(p=0.040)$ were statistically significant for PFS (Table III).

In multivariate analysis, KPS $\geq 70$ (HR:2.96, 95\% Cl:1.68-5.21; $\mathrm{p}<0.001$ ), type of surgical resection (HR:2.32, 95\% Cl:1.353.98; $p=0.002$ ) were statistically significant for PFS (Table IV).

The median OS for PLR $<150$ was 17 months $(p=0.005)$, NLR $<4$ was 17 months $(p=0.001)$ too. These were statiscically significant. Age, gender, Ki-67 ratio, adjuvant chemotherapy apply, IDH-ATRX-EGFR molecular analysis were not statistically significant. Median OS was 17 months in patients undergoing total resection $(p=0,032)$ and $K P S \geq 70$ patients $(p<0.001)$.

In univariate analysis $\operatorname{PLR}<150(p=0.005), N L R<4 \quad(p=0.010)$, KPS $\geq 70 \quad(p<0.001)$, total surgical resection $(p=0.032)$ were statistically significant for OS (Table V).

In multivariate analysis, KPS $\geq 70$ (HR:2.72, 95\% Cl:1.30$5.67 ; \mathrm{p}<0.007$ ), type of surgical resection (HR:2.09, 95\% $\mathrm{Cl}: 1.10-3.95 ; \mathrm{p}=0.023), \mathrm{NLR}>4$ (HR:2.14, 95\% Cl:1.11-4.14; $\mathrm{p}=0.023$ ) were statistically significant for OS were found to be independent prognostic factor (Table VI).
The median OS was significantly shorter in PLR>150 patients (10 vs 17 months; $p=0.005$ ) (Figure 2).

The median OS was significantly shorter in NLR $>4$ patients (11 vs 17 months) $(p=0.010)$ (Figure 3).

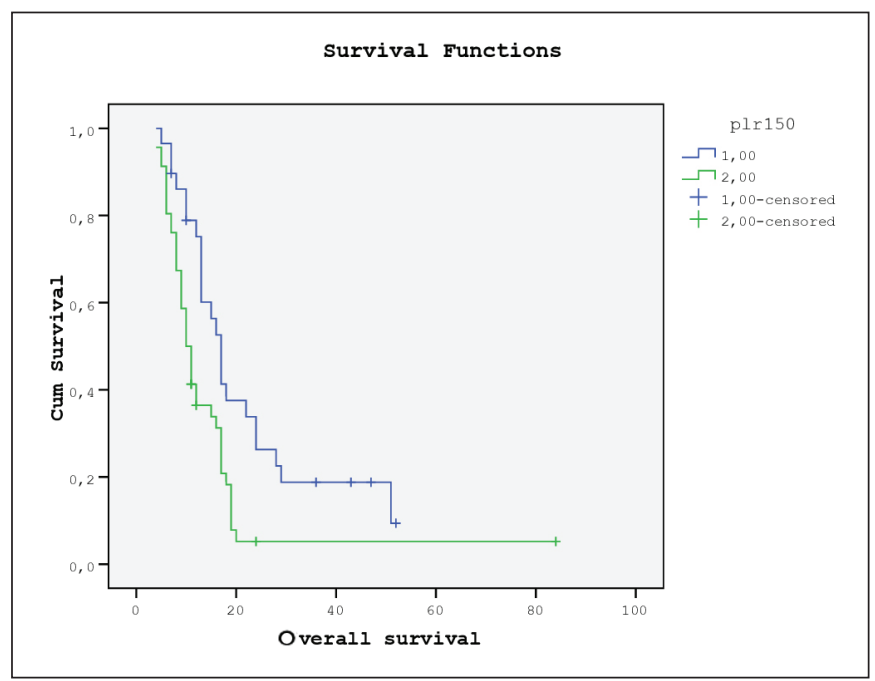

Figure 2: OS for PLR>150 and PLR $\leq 150$ patients.

Table III: Univariate Cox Regression Analyses for Progression Free Survival

\begin{tabular}{|c|c|c|c|c|}
\hline Univariate analyses & 1 year PFS (\%) & 2 year PFS (\%) & Median PFS (month) & p \\
\hline \multicolumn{5}{|l|}{ PLR } \\
\hline$\leq 150$ & 41 & 11 & 9 & \multirow{2}{*}{0.060} \\
\hline$>150$ & 24 & 5 & 8 & \\
\hline \multicolumn{5}{|l|}{ NLR } \\
\hline$\leq 4$ & 32 & 16 & 9 & \multirow{2}{*}{0.068} \\
\hline$>4$ & 27 & 4 & 8 & \\
\hline \multicolumn{5}{|l|}{ Surgery } \\
\hline Total resection & 47 & 7 & 11 & \multirow{2}{*}{0.040} \\
\hline Subtotal resection & 16 & 6 & 7 & \\
\hline \multicolumn{5}{|l|}{ KPS } \\
\hline$\geq 70$ & 41 & 11 & 10 & \multirow{2}{*}{0.002} \\
\hline$<70$ & 9 & - & 7 & \\
\hline
\end{tabular}

PLR: Platelet to lymphocyte ratio, NLR: Neutrophyl to lymphocyte ratio, KPS: Karnoffsky performance score.

Table IV: Multivariate Cox Regression Analyses for Progression Free Survival

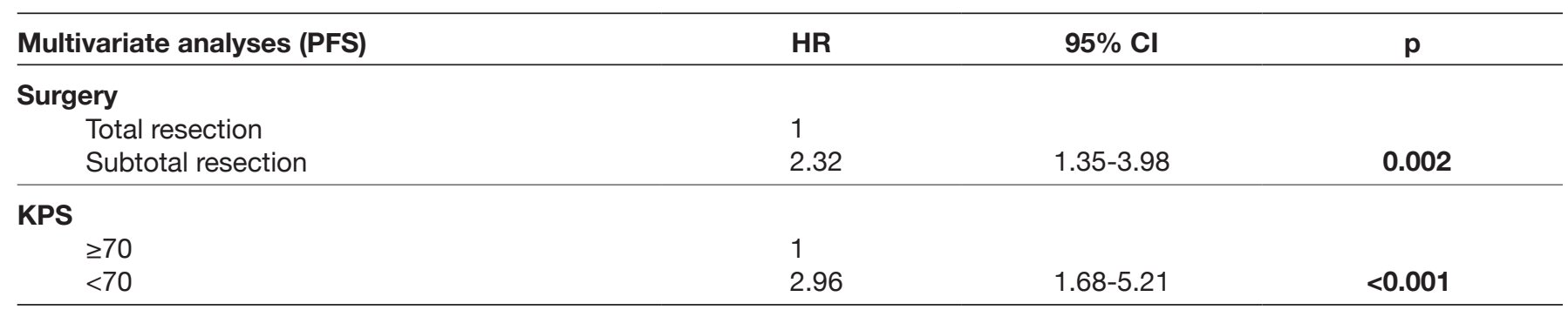

KPS: Karnofsky performance score. 
Table V: Univariate Cox Regression Analyses for Overall Survival

\begin{tabular}{|c|c|c|c|c|}
\hline Univariate analyses & 1 year OS (\%) & 2 year OS (\%) & Median OS (month) & $\mathbf{p}$ \\
\hline \multicolumn{5}{|l|}{ PLR } \\
\hline$\leq 150$ & 75 & 34 & 17 & \multirow{2}{*}{0.005} \\
\hline$>150$ & 41 & 5 & 10 & \\
\hline \multicolumn{5}{|l|}{ NLR } \\
\hline$\leq 4$ & 76 & 41 & 17 & \multirow{2}{*}{0.010} \\
\hline$>4$ & 45 & 7 & 11 & \\
\hline \multicolumn{5}{|l|}{ Age } \\
\hline$\leq 50$ & 82 & 19 & 17 & \multirow{2}{*}{0.070} \\
\hline$>50$ & 47 & 16 & 11 & \\
\hline \multicolumn{5}{|l|}{ Gender } \\
\hline Female & 46 & 12 & 11 & \multirow{2}{*}{0.327} \\
\hline Male & 59 & 20 & 17 & \\
\hline \multicolumn{5}{|l|}{ Ki-67 ratio } \\
\hline$\leq 10$ & 45 & 10 & 11 & \multirow[b]{2}{*}{0.225} \\
\hline$>10$ & 57 & 18 & 15 & \\
\hline \multicolumn{5}{|l|}{ KPS } \\
\hline$\geq 70$ & 67 & 27 & 17 & \multirow[b]{2}{*}{$<0.001$} \\
\hline$<70$ & 35 & - & 9 & \\
\hline \multicolumn{5}{|l|}{ Surgery } \\
\hline Total resection & 80 & 14 & 17 & \multirow{2}{*}{0.032} \\
\hline Subtotal resection & 35 & 14 & 10 & \\
\hline \multicolumn{5}{|l|}{ Adjuvant chemotherapy } \\
\hline Absent & 17 & - & 10 & \multirow{2}{*}{0.343} \\
\hline Present & 57 & 18 & 13 & \\
\hline \multicolumn{5}{|l|}{ IDH } \\
\hline Negative & 47 & 11 & 11 & \multirow{2}{*}{0.066} \\
\hline Positive & 61 & 22 & 17 & \\
\hline \multicolumn{5}{|l|}{ ATRX } \\
\hline Negative & 60 & 20 & 17 & \multirow{2}{*}{0.901} \\
\hline Positive & 58 & 14 & 16 & \\
\hline \multicolumn{5}{|l|}{ EGFR } \\
\hline Negative & 43 & 9 & 10 & \multirow{2}{*}{0.286} \\
\hline Positive & 62 & 21 & 17 & \\
\hline
\end{tabular}

PLR: Platelet to lymphocyte ratio, NLR: Neutrophyl to lymphocyte ratio, KPS: Karnofsky performance score, IDH: Isocitrate dehydrogenase, ATRX: $\alpha$ thalassemial mental retardation syndrome X-linked, EGFR: Epidermal growth factor.

Table VI: Multivariate Cox Regression Analyses for Overall Survival

\begin{tabular}{|c|c|c|c|}
\hline Multivariate analyses (OS) & HR & $95 \% \mathrm{Cl}$ & $\mathbf{p}$ \\
\hline \multicolumn{4}{|l|}{ Surgery } \\
\hline Gross total resection & 1 & & \\
\hline Subtotal resection & 2.09 & $1.10-3.95$ & 0.023 \\
\hline \multicolumn{4}{|l|}{ NLR } \\
\hline$\leq 4$ & 1 & & \\
\hline$>4$ & 2.14 & $1.11-4.14$ & 0.023 \\
\hline \multicolumn{4}{|l|}{ KPS } \\
\hline$\geq 70$ & 1 & & \\
\hline$<70$ & 2.72 & $1.30-5.67$ & 0.007 \\
\hline
\end{tabular}

NLR: Neutrophyl to lymphocyte ratio, KPS: Karnofsky performance score. 


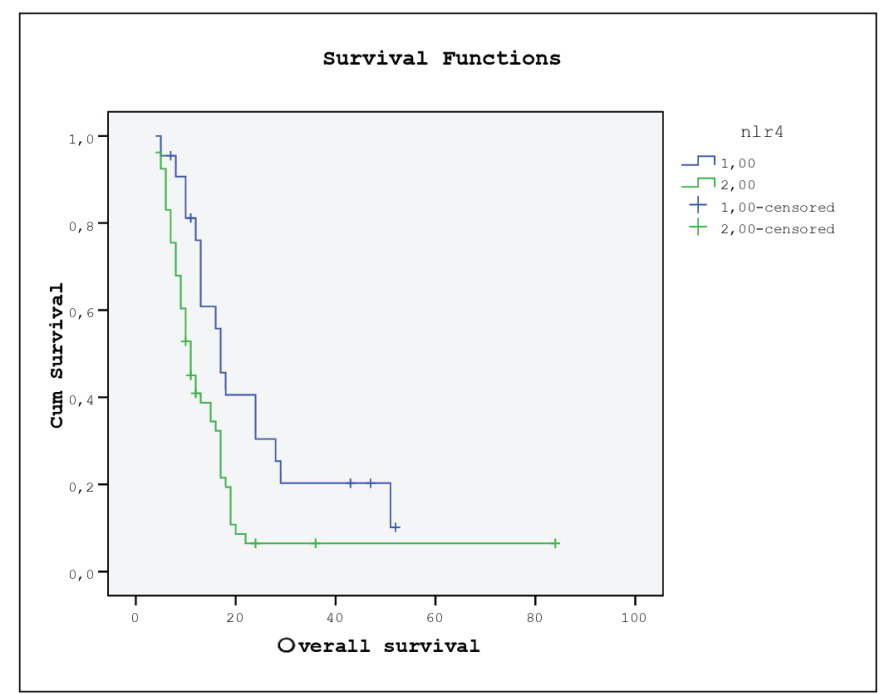

Figure 3: $O S$ for $N L R>4$ and $N L R \leq 4$ patients.

\section{Limitations}

Some prejudices may be in this study. This was a retrospective research, first of all. And we were not analyze different prognostic factors and connections between in this study,like IDH-1 mutations, EGFR, ATRX etc. These crucial parameters are not known for all patients. MGMT status was not known too. Yet, this study concentreated on the connection between preoperatively hematological markers and clinical outcomes in GBM. When we look at these, they illustrate our limitations.

\section{DISCUSSION}

The relationship between hematological parameters for the prognoses of patients with GBMs are little known. NLR and PLR of GBM patients for PFS and OS were assessed limited number of studies, but the results are not clear. Some studies have demonstrate that high preoperative NLR is connected with bad prognosis and lower survival in GBM patients.PLR, another inflammatory marker, has been less researched as a prognostic factor in cancer patients compared to NLR.

As we know, $70<$ KPS value is worse survival indicator than the $70 \geq$ KPS value. In Simpson et al.'s study, in patients with gross total resection, in the frontal region of the tumor and high KPS ratio and $<40$ years in GBM patients were observed the best OS (14). In our study, we observed better OS in patients with gross total resection and KPS $\geq 70$ in accordance with the literature.

The outcomes of present study assess the relationship among with preoperative neutrophil-to-lymphocyte ratio and plateletlymphocyte ratio, progression free survival and overall survival in patients with GBM. In our study, we observed that patients with high NLR values were associated with a poor OS and this was statistically significant. NLR elevation is associated with poor survival. The other marker, PLR was not significantly correlated with progression free survival or overall survival.
According to Lopes et al. in the subgroup analysis of patients who completed the stupp protocol, a higher NLR>7 was an independent prognostic factor in GBM patients for a poor overall survival (9). Mason et al. analyzed NLR values in postoperative GBM patients who generally taken corticosteroids, which effect the NLR values, and referred a cut-off value of 7.5. (11) That NLR values is very high compared ours. In our study, we found cut off value 4 for NLR.

Han et al. during a study conducted by 154 patients with glioblastoma, NLR was reported to be associate independent prognostic factor for survival (6). But, PLR was not significant prognostic factor for survival in multivariate analysis. We found that high NLR are related to poor prognosis and PLR is'nt significant prognostic factor as in Han et al.'s results.

Kaya et al. have confirmed that NLR may be used as a prognostic factor in glioblastomas patients based on peripheral blood counts prior to treatment, like us (8).

Neutrophil and lymphocyte counts are non-specific parameters which will be littered with coincident conditions like infection, inflammation, and medications (22). The bloodbrain barrier is usually impaired in glioblastomas, which permit circulating lymphocytes to pass through (12). In cancer patients the quantitiy of neutrophils increases. This brings a relative decrease in the lymphocyte diversity. Thus, the tumour cells are suppress the immune cells. The mechanism of the increase in neutrophils and the decrease in lymphocytes has not been obviously detected $(21,23)$. In present study, we found that the median lymphocyte level was lower with 1.6 (range:0.5-3.0) and also the neutrophil level was higher with 7.0 (range:2.4-22.0).

Zadora et al. retrospectively examined 424 patients with brain tumors and determinant a major relationship between tumour grade and NLR. The cut-off value of NLR was upper in glioblastoma patients and was 2,5 (21). This was lower than our study.

Bambury et al. examined the effect of SIR on prognosis in glioblastoma patients based on a retrospective evaluation of the patients. They considered SIR to be present in patients with NLR> 4 . They also reported that the based on multivariate analysis the presence of SIR was an independent poor prognostic factor (2). In this study, we found that the prognosis was badly in patients with NLR $>4$ patients.

Wang et al. taking into account the incidence of IDH mutation, assessed the prognostic value of NLR, PLR and LMR in glioblastoma patients, In patients with GBM, PLR and NLR have independent prognostic values (19). Hematological markers NLR, PLR were not related with IDH mutations in our study.

\section{CONCLUSION}

In present study, we found that prognostic factors that could be effective in GBM and our results in terms of progression free survival and overall survival were consistent with literature. In the future, we think that the findings of our retrospective 
study will be confirmed by prospective studies. Preoperative higher NLR value is meaningful prognostic indicator for GBM patients.

\section{REFERENCES}

1. Alexiou GA, Vartholomatos E, Voulgaris S: Prognostic value of neutrophil-to-lymphocyte ratio in patients with glioblastoma. J Neurooncol 115:521-522, 2013

2. Bambury RM, Teo MY, Power DG, Yusuf A, Murray S, Battley JE, Drake C, O'Dea P, Bermingham N, Keohane C, Grossman SA, Moylan EJ, O'Reilly S: The association of pre-treatment neutrophil to lymphocyte ratio with overall survival in patients with glioblastoma multiforme. J Neurooncol 114:149-154, 2013

3. Forrest LM, McMillan DC, McArdle CS, Angerson WJ, Dunlop DJ: Evaluation of cumulative prognostic scores based on the systemic inflammatory response in patients with inoperable non-small cell lung cancer. Br J Cancer 89:1028-1030, 2003

4. Gu X, Gao X, Li X, Qi X, Ma M, Qin S, Yu H, Sun S, Zhou D, Wang W: Prognostic significance of neutrophil-to-lymphocyte ratio in prostate cancer: Evidence from 16,266 patients. Sci Rep 6:22089, 2016

5. Gunaldi M, Goksu S, Erdem D, Gunduz S, Okuturlar Y, Tiken E, Kahraman S, Inan YO, Genc TB, Yıldırım M: Prognostic impact of platelet/lymphocyte and neutro-phil/lymphocyte ratios in patients with gastric cancer: A multicenter study. Int J Clin Exp Med 8:5937-5942, 2015

6. Han S, Liu Y, Li Q, Li Z, Hou H, Wu A: Pre-treatment neutrophilto-lymphocyte ratio is associated with neutrophil and T-cell infiltration and predicts clinical outcome in patients with glioblastoma. BMC Cancer 15:617, 2015

7. Hwang KT, Chung JK, Roh EY, Kim J, Oh S, Kim YA, Rhu J, Kim S: Prognostic influence of preoperative fibrinogen to albumin ratio for breast cancer. J Breast Cancer 20(3):254263, 2017

8. Kaya V, Yıldırım M, Yazıcı G, Yalcın AY, Orhan N, Guzel A: Prognostic significance of indicators of systemic inflammatory responses in glioblastoma patients. Asian Pac J Cancer Prev 18(12):3287-3291, 2017

9. Lopes M, Carvalho B, Vaz R, Linhares P: Influence of neutrophil-lymphocyte ratio in prognosis of glioblastoma multiforme. J Neurooncol 136:173-180, 2018

10. Louis DN, Ohgaki H, Wiestler OD, Cavenee WK, Burger PC, Jouvet A, Scheithauer BW, Kleihues P: The 2007 WHO classification of tumours of the central nervous system. Acta Neuropathol 114:97-109, 2007

11. Mason M, Maurice C, McNamara MG, Tieu MT, Lwin Z, Millar BA, Menard C, Laperriere N, Milosevic M, Atenafu EG, Mason W, Chung C: Neutrophil-lymphocyte ratio dynamics during concurrent chemo-radiotherapy for glioblastoma is an independent predictor for overall survival. J Neurooncol 132:463-471, 2017

12. Muller C, Holtschmidt J, Auer M, Heitzer E, Lamszus K, Schulte A, Matschke J, Langer-Freitag S, Gasch C, Stoupiec M, Mauermann O, Peine S, Glatzel M, Speicher MR, Geigl JB, Westphal M, Pantel K, Riethdorf S: Hematogenous dissemination of glioblastoma multiforme. Sci Transl Med 6:247ra101, 2014
13. Perisanidis C, Psyrri A, Cohen EE, Engelmann J, Heinze G, Perisanidis B, Stift A, Filipits M, Kornek G, Nkenke E: Prognostic role of pretreatment plasma fibrinogen in patients with solid tumors: A systematic review and meta-analysis. Cancer Treat Rev 41(10):960-970, 2015

14. Simpson JR, Horton J, Scott C, Curran WJ, Rubin P, Fischbach J, Isaacson S, Rotman M, Asbell S, Nelson JS: Influence of location and extent of surgical resection on survival of patients with glioblastoma multiforme: Results of three consecutive Radiation Therapy Oncology Group (RTOG) clinical trials. Int J Radiat Oncol Biol Phys 26(2):239-244, 1993

15. Stupp R, Mason WP, van den Bent MJ, Weller M, Fisher B, Taphoorn MJB, Belanger K, Brandes AA, Marosi Cı, Bogdahn U, Curschmann J, Janzer RC, Ludwin SK, Gorlia T, Allgeier bir, Lacombe D, Cairncross JG, Eisenhauer E, Mirimanoff RO: Radiotherapy plus concomitant and adjuvant temozolomide for glioblastoma. N Engl J Med 352:987-996, 2005

16. Templeton AJ, McNamara MG, Seruga B, Vera-Badillo FE, Aneja P, Ocana A, Leibowitz-Amit R, Sonpavde G, Knox JJ, Tran B, Tannock IF, Amir E: Prognostic role of neutrophil-tolymphocyte ratio in solid tumors: A systematic review and meta-analysis. J Natl Cancer Inst 106:124, 2014

17. Turkdogan KA, Eren SH, Coskun A, Engin A, Sonmez E, Civelek C: Ratio of neutrophil to lymphocyte counts in crimean congo hemorrhagic fever. J Clin Anal Med 7:10-13, 2016

18. Van Soest RJ, Templeton AJ, Vera-Badillo FE, Mercier F, Sonpavde G, Amir E, Tombal B, Rosenthal M, Eisenberger MA, Tannock IF, de Wit R: Neutrophil-to-lymphocyte ratio as a prognostic biomarker for men with metastatic castrationresistant prostate cancer receiving first-line chemotherapy: Data from two randomized phase III trials. Ann Oncol 26:743749, 2015

19. Wang PF, Song HW, Cai HQ, Kong LW, Yao K, Jiang T, Li SW, Yan CX: Preoperative inflammation markers and IDH mutation status predict glioblastoma patient survival. Oncotarget 8:50117-50123, 2017

20. You J, Zhu GQ, Xie L, Liu WY, Shi L, Wang OC, Huang ZH, Braddock M, Guo GL, Zheng MH: Preoperative platelet to lymphocyte ratio is a valuable prognostic biomarker in patients with colorectal cancer. Oncotarget 7:25516-25527, 2016

21. Zadora P, Dabrowski W, Czarko K, Smolen A, KotlinskaHasiec E, Wiorkowski K, Sikora A, Jarosz B, Kura K, Rola R, Trojanowski T: Preoperative neutrophil-lymphocyte count ratio helps predict the grade of glial tumor - a pilot study. Neurol Neurochir Pol 49:41-44, 2015

22. Zhao Z, Zhao X, Lu J, Xue J, Liu P, Mao H: Prognostic roles of neutrophil to lymphocyte ratio and platelet to lymphocyte ratio in ovarian cancer: A meta-analysis of retrospective studies. Arch Gynecol Obstet 297(4):849-857, 2018

23. Zheng SH, Huang JL, Chen M, Wang BL, Ou QS, Huang SY: Diagnostic value of preoperative inflammatory markers in patients with glioma: A multicenter cohort study. J Neurosurg 3:1-10, 2017 